\title{
Vertical Extent of Thunderstorm Inflows Revealed by Polarimetric Radar*
}

\author{
VALERY MELNIKOV \\ Cooperative Institute for Mesoscale Meteorological Studies, University of Oklahoma, and NOAA/OAR/National \\ Severe Storms Laboratory, Norman, Oklahoma \\ DUŠAN S. ZRNIĆ \\ NOAA/OAR/National Severe Storms Laboratory, Norman, Oklahoma \\ DONALD W. BURGESS \\ Cooperative Institute for Mesoscale Meteorological Studies, University of Oklahoma, and NOAA/OAR/National \\ Severe Storms Laboratory, Norman, Oklahoma \\ EDWARD R. MANSELL \\ NOAA/OAR/National Severe Storms Laboratory, Norman, Oklahoma
}

(Manuscript received 20 April 2015, in final form 28 July 2015)

\begin{abstract}
It is shown that the dual-polarization radar parameters can be used to estimate the vertical extent of inflow regions in thunderstorms. Atmospheric biota trapped by inflows allows identification of inflow regions. It is shown that weak echoes from biota can be observed at signal-to-noise ratios as low as $-7 \mathrm{~dB}$. The vertical extent of inflow reached $5.2 \mathrm{~km}$ in the analyzed tornadic thunderstorm and $6.7 \mathrm{~km}$ in a severe thunderstorm.
\end{abstract}

\section{Introduction}

The location of inflow is informative in obtaining a dynamical structure of a thunderstorm. Information about inflow and updraft locations is important in operational use of weather radar when signatures are used in warning decisions (Burgess and Lemon 1990). The classic approach of identifying inflow areas in radar images is looking for a weak echo region (WER) in a reflectivity field (e.g., Browning 1982, 1983; Schiesser and Waldvogel 1999). A Doppler radial velocity field is frequently difficult to interpret because the true inflow velocity can be estimated only when the direction of a radar beam coincides with the direction of inflow, which is a rare occasion.

\footnotetext{
* Supplemental information related to this paper is available at the Journals Online website: http://dx.doi.org/10.1175/JTECH-D-15-0096.s1.

Corresponding author address: Valery Melnikov, CIMMS, University of Oklahoma, 120 David L. Boren Blvd., Room 4949, Norman, OK 73072.

E-mail: valery.melnikov@noaa.gov
}

Studying convergence areas that led to formation of convective clouds, Wilson et al. (1994) came to the conclusion that radar detects such areas because of enhanced concentration of insects, tree leaves, and lofted grass. Wakimoto et al. (2004) hypothesized that insects, swept by a strong inflow, may penetrate deep into convective clouds. Direct observations of insects trapped in an inflow were made by Murphey et al. (2006) using onboard Doppler radar. Nonpolarimetric Doppler radars have been used in these studies. Dual-polarization radar capabilities allow for identification of echoes from atmospheric biota, such as birds and insects (e.g., Zrnić and Ryzhkov 1999). In this paper, we explore the use of dual-polarization parameters to identify the origin of scatterers in WERs and show that inflow areas can stretch to heights where WERs are not exhibited.

\section{Utilizing the dual-polarization parameters to indicate inflow areas}

Six radar variables are measured with polarimetric Doppler weather radars; these are equivalent reflectivity 

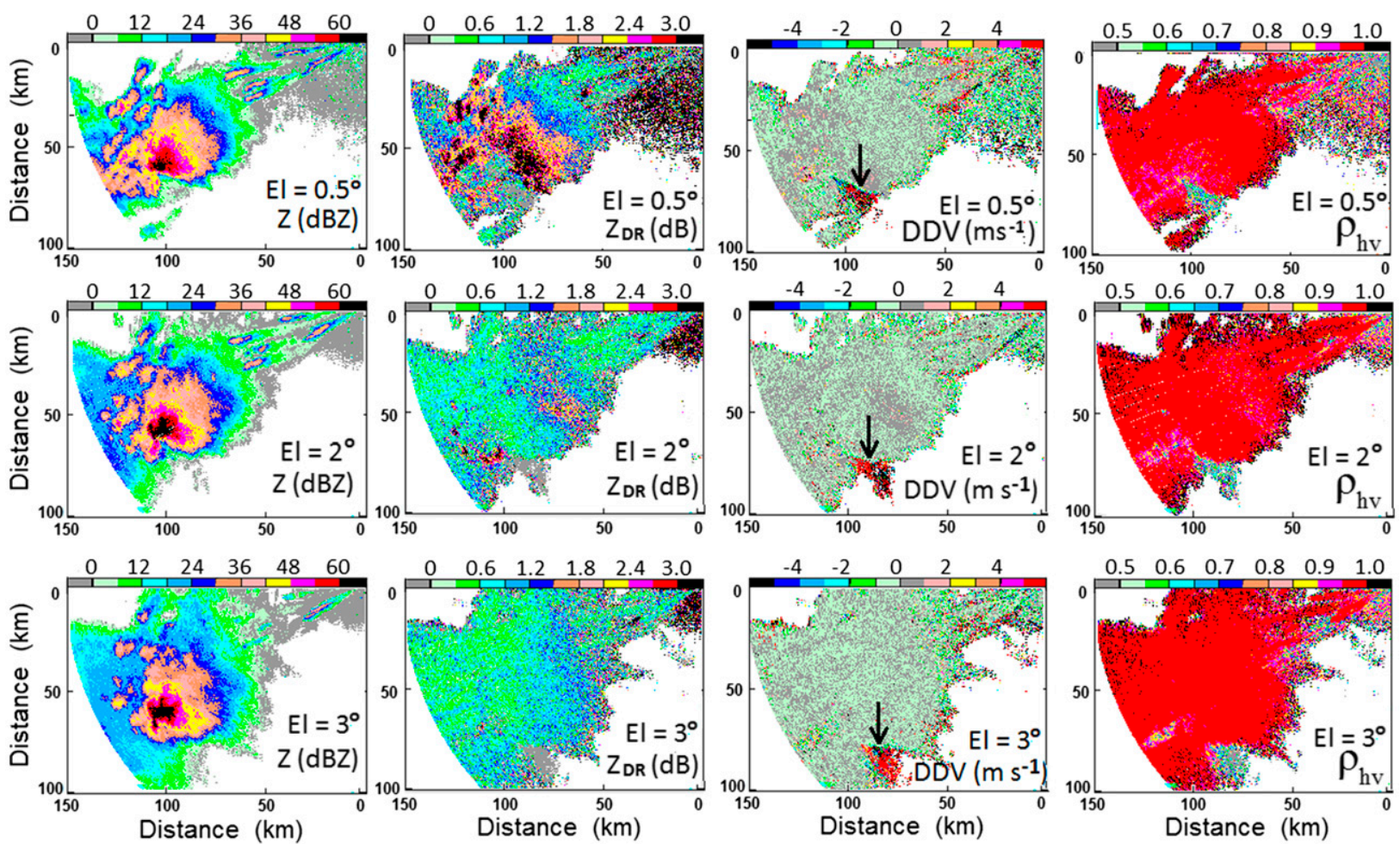

FIG. 1. Fields of reflectivity, Doppler velocity, DDV, and CC $\left(\rho_{\text {hv }}\right)$ collected by the dual-polarization WSR-88D KOUN at 2217 UTC 17 Apr 2013 at antenna elevations of $0.5^{\circ}, 2^{\circ}$, and $3^{\circ}$ (shown in corresponding rows). The reflectivity field has been generated at $\mathrm{SNR} \geq-2 \mathrm{~dB}$, and the dual-polarization fields have been obtained at $\mathrm{SNR} \geq-7 \mathrm{~dB}$.

factor $(Z)$, Doppler velocity $(V)$, spectrum width $(W)$, differential reflectivity $\left(Z_{\mathrm{DR}}\right)$, differential phase $\left(\Phi_{\mathrm{DP}}\right)$, and correlation coefficient $\left(\mathrm{CC}\right.$ or $\left.\rho_{\mathrm{hv}}\right)$. Reflectivity and the Doppler velocity $\left(V_{h}\right)$ are measured at horizontal polarization. We consider herein also a new dualpolarization parameter, the difference of Doppler velocities (DDV) obtained as the difference of the velocities measured at horizontal and vertical polarizations, that is, DDV $=V_{h}-V_{v}$. In weather echoes, the absolute values of DDV are typically less than $1 \mathrm{~m} \mathrm{~s}^{-1}$ (Metcalf 1986; Wilson et al. 1997). Melnikov et al. (2014) showed that in radar echoes from insects and birds, DDV values are frequently larger than those in weather echoes and can exceed $5 \mathrm{~m} \mathrm{~s}^{-1}$.

Figure 1 shows data collected with the dualpolarization WSR-88D KOUN, located in Norman, Oklahoma. This thunderstorm produced hail with diameters up to $2 \mathrm{~cm}$. A well-pronounced WER is seen in $Z$ fields at the southern edge of the thunderstorm at an antenna elevation of $0.5^{\circ}$ (Fig. $1 ; Z$ field, about $100 \mathrm{~km}$ west and $70 \mathrm{~km}$ south from the radar). The WER is seen at higher elevations up to $2^{\circ}$ (Fig. 1 and Fig. S1). The identification of inflow in the Doppler velocity field is ambiguous because the radar beam is almost orthogonal to the inflow direction, which can be deduced to be southeasterly by looking at the WER's configuration. Some decrease in the Doppler velocities in the WER (Fig. S1) is an indirect indication of the inflow. One can see negative $Z_{\mathrm{DR}}$, high DDV, and low CC values in the WER (Fig. 1), indicating nonmeteorological scatterers such as insects, birds, or light debris. In the weather echo, the absolute DDV values are lower than $1 \mathrm{~m} \mathrm{~s}^{-1}$ (Figs. 1 and Fig. S2). The WER and areas close to the radar exhibit large DDV values characteristic of echoes from insects and birds (Melnikov et al. 2014). Some streaks of large DDVs near the radar are caused by second trip echoes.

At an elevation of $3^{\circ}$, the WER in the $Z$ field is absent but an area of negative $Z_{\mathrm{DR}}$, enhanced DDV, and low $\mathrm{CC}$ values is still present. We submit that the inflow region stretches up to this elevation. At the next available elevation of $4^{\circ}$, this feature disappears in the fields of dual-polarization variables, leading us to conclude that the inflow area stretches from the ground up to at least $4.3 \mathrm{~km}$ above ground. The top of the layer of atmospheric biota, obtained in areas away from the thunderstorm, is at a height of $0.9 \mathrm{~km}$, which is much lower than the top of the biota column in the WER. The temperature at a height of $4.3 \mathrm{~km}$ is about $-2^{\circ} \mathrm{C}$, that is, below freezing (sounding 0000 UTC 18 April 2013 at 

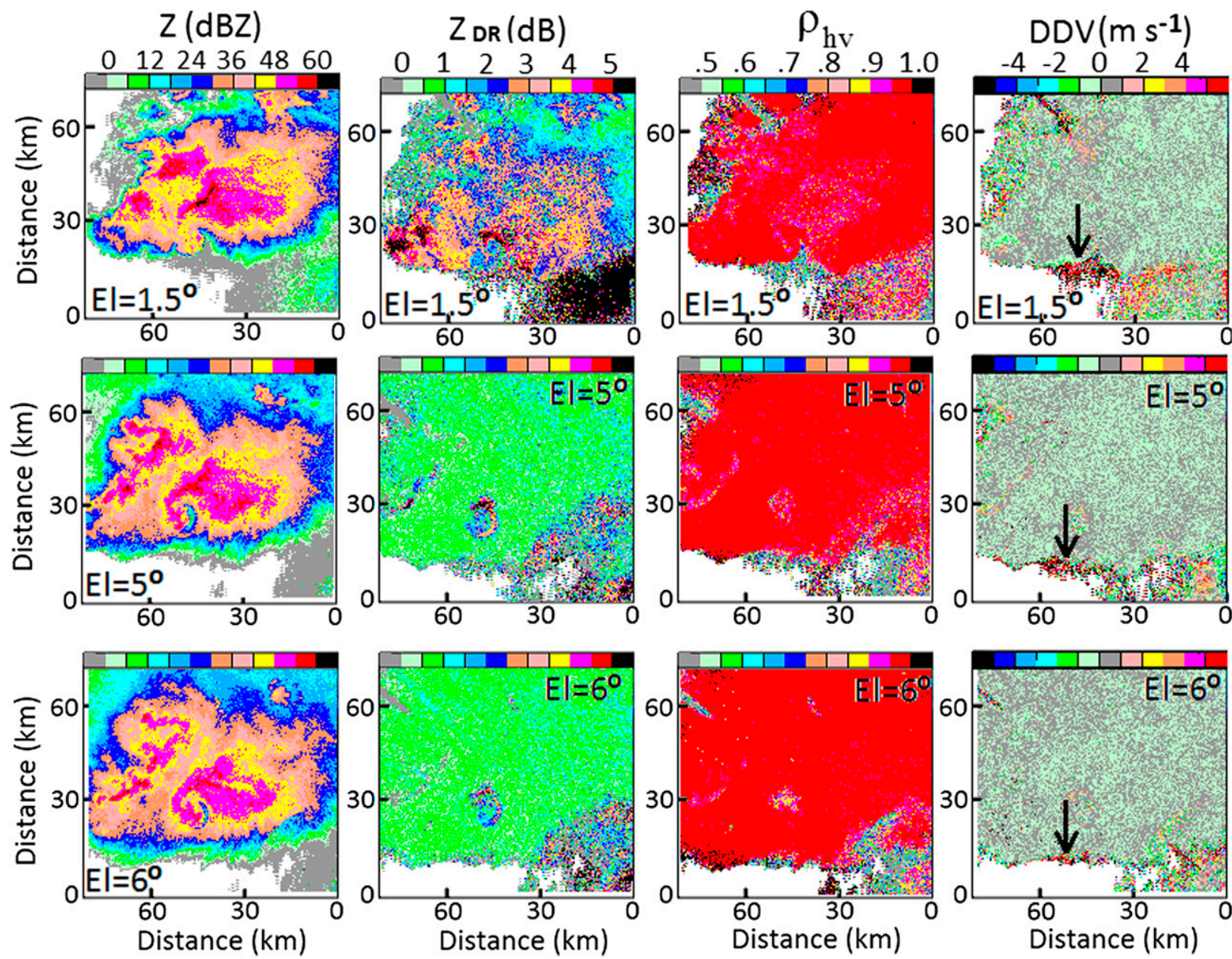

FIG. 2. As in Fig. 1, but at 2315 UTC 31 May 2013.

Lamont, Oklahoma; data from OUN are not available from this height). Insects fly in air with temperatures above $5^{\circ} \mathrm{C}$ (Achtemeier 1991; Drake and Reynolds 2012, 234-235). Therefore, we conclude that the updraft stronger than the insects' downward velocities raised the insects so high. Thus, dual polarization can be used to estimate the vertical extent of the inflow. It is remarkable that the features are seen at distances as large as $80 \mathrm{~km}$.

Return signals from the WER area are weak. To enhance detectability the two-dimensional noise despeckling procedure of Melnikov and Schlatter (2011) has been applied. It enables reasonable quantitative estimation of $Z, V$, and $W$ fields at signal-to-noise ratios (SNR) as low as $-2 \mathrm{~dB}$. The despeckling procedure yields good estimates of polarimetric variables down to an SNR of $-7 \mathrm{~dB}$. This improvement is possible because noise speckles at horizontal and vertical polarizations are independent, so that simultaneous presence of noise speckles at the same range location is much less likely than the presence of a speckle of one polarization at that range location.

The second example presents a tornadic thunderstorm that occurred on 31 May 2013 near El Reno, Oklahoma (Fig. 2). A hook echo at the southern edge of the thunderstorm, indicative of strong inflow, is clearly seen; see also Snyder and Bluestein (2014) for the identification of tornado debris with high-resolution mobile radar. The dual-polarization variables in areas close to the hook echo suggest the presence of biota trapped in the inflow. Similar values of dual-polarization variables are also observed along the entire southern edge of the thunderstorm, where the concentration of insects/birds is enhanced by the approaching storm. Echoes of biota close to the hook echo can be seen from the ground to an elevation of $6^{\circ}$, implying that the inflow stretches up to $5.2-\mathrm{km}$ height (range of $50 \mathrm{~km}$ ). At the $6^{\circ}$ elevation, the WER is absent but a bounded weak echo 

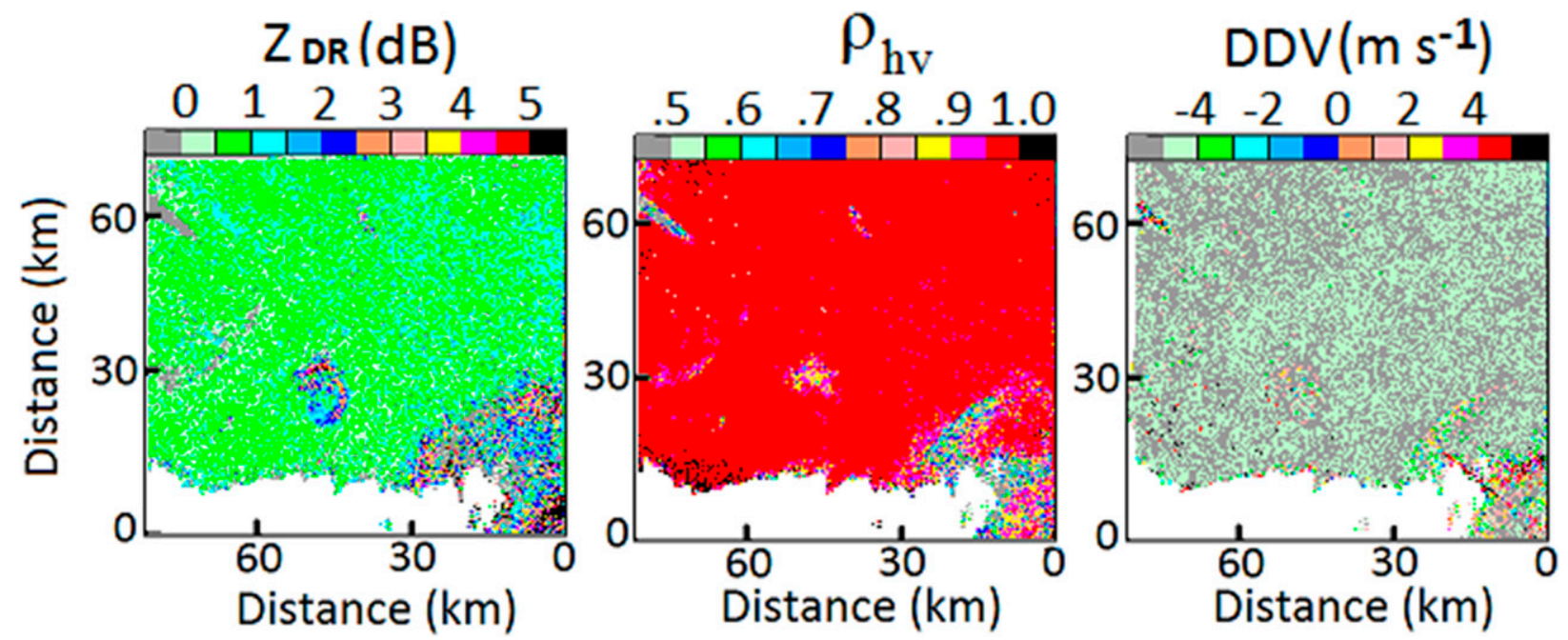

FIG. 3. Differential phase fields as in the bottom row in Fig. 2, but shown at SNR $\geq 2 \mathrm{~dB}$.

region (BWER) is present. The fields of single- and dual-polarization variables at all available elevations are in Figs. S3 and S4. The temperature at a height of $5.2 \mathrm{~km}$ is near $-3^{\circ} \mathrm{C}$ (OUN at 0000 UTC 1 June 2013), which is not favorable for insect flights. The presence of insect there we attribute to lofting by the strong updraft.

The standard (default) SNR threshold used in operational WSR-88Ds is $2 \mathrm{~dB}$. At this and higher SNRs, weak echoes from biota may not be seen as demonstrated in Fig. 3 (cf. Fig. 3, where there are no areas of enhanced DDV in the vicinity of the tornado area, with the three corresponding panels in the bottom row in Fig. 2). Detectability of weak features in the polarimetric variables at lower SNRs could be important for identifying the tops of inflow areas. In the case of the 17 April 2013 event, very small biota echoes are still visible (two bottom-right panels in Fig. S5 in the same locations as in the corresponding top panels).

Figure 4 presents an example of vertical cross sections of a thunderstorm that does not exhibit a wellpronounced WER. The top of the biota layer in the "clear air" areas is at $3 \mathrm{~km}\left(T=11^{\circ} \mathrm{C}, \mathrm{OUN}, 1200 \mathrm{UTC}\right.$ 9 August 2007). The Doppler velocity field shows increased horizontal flows in areas of enhanced DDV at $80-95 \mathrm{~km}$ from the radar, indicating the inflow area. The column of enhanced DDV and low $\rho_{\text {hv }}$ stretches up to $6.7 \mathrm{~km}\left(T=-10^{\circ} \mathrm{C}\right)$, that is, much higher than the top of the biota layer in areas away from the thunderstorm. This feature along with the Doppler velocity field allows for concluding that the inflow stretches up to $6.7 \mathrm{~km}$. The presence of insects at the subfreezing temperature is due to the strong updraft.

One of the anonymous reviewers suggested that the identification of boundary layer air with generally higher equivalent temperatures as a major component in the WER region could be more important for the forecasters than the top of inflows.

To interpret large DDV values in echoes from biota, Doppler spectra at two polarizations are considered. An example is in Fig. 5 from the inflow area observed at 2315 UTC 31 May 2013. The main spectral peaks at the two polarizations are at about $16 \mathrm{~m} \mathrm{~s}^{-1}$. Beside this coincidence the spectra are very broad and exhibit significant differences. That and the differences in spectral amplitudes and phases cause a difference in phases, leading to the decrease of the correlation coefficient to 0.60 , which is well below usual precipitation values. The mean Doppler velocities are $V_{h}=13.7$ and $V_{v}=$ $20.2 \mathrm{~m} \mathrm{~s}^{-1}$, so that DDV $=-6.5 \mathrm{~m} \mathrm{~s}^{-1}$. We speculate the spectra are broad and different because this radar volume is filled with various species reacting differently to strong inflow.

\section{Conclusions}

Obtaining inflow parameters from a Doppler velocity field is frequently not easy because it requires the inflow velocity to be parallel to the radar beam, which is a rare occasion. However, information about inflow direction and magnitude is needed for warning decisions. Inflow areas are usually identified by observing the weak echo region (WER) in a reflectivity field. Using a dualpolarization radar, we show that the WERs are filled with atmospheric biota trapped by inflows. The tops of analyzed inflows are located much higher than the tops of biota layers observed outside the thunderstorms, which suggests that the insects' downward velocities are not sufficient to overcome the updraft velocities. 

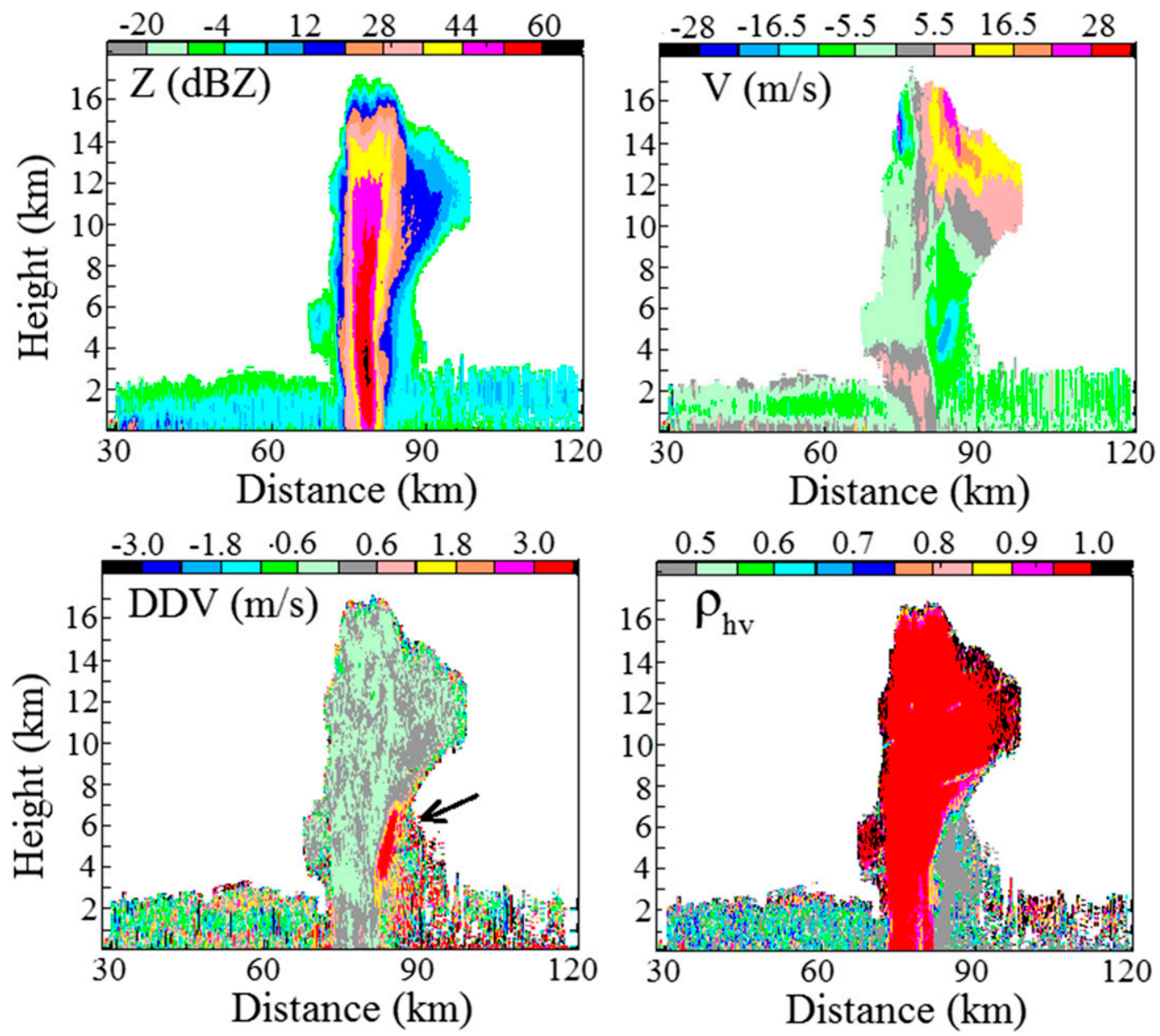

FIG. 4. Vertical cross sections of a thunderstorm observed with KOUN at 1426 UTC 9 Aug 2007 at an azimuth of $330^{\circ}$.

An inflow region is identified as a contiguous area of echoes from biota at increasing radar antenna elevations. The highest elevation with low correlation coefficients (CC) and enhanced difference of Doppler velocities (DDV) values can be used to estimate the inflows' vertical extent. At such elevations, the WER may be absent. Using this approach, we estimated the maximal heights of inflows to be about 4.3 (Fig. 1) and $6.7 \mathrm{~km}$ (Fig. 4) in nontornadic thunderstorms and $5.2 \mathrm{~km}$ in tornadic thunderstorms (Fig. 2).

DDV appears to be a good indicator of atmospheric biota. The DDV in the WERs have absolute values that are much larger than those in weather echoes. DDV is a more robust parameter in weak radar echo than CC because $\mathrm{CC}$ is more prone to degradation by noise. Very accurate estimations of noise in the polarimetric channels are required to obtain reliable $\mathrm{CC}$ values but the Doppler velocity is not biased by noise.

It is demonstrated that meaningful dual-polarization fields can be obtained at signal-to-noise ratios as low as $-7 \mathrm{~dB}$. Such a low SNR is needed for observations of weak biota echoes. Such weak echoes can be filtered out at $\mathrm{SNR} \geq 2 \mathrm{~dB}$, which is used in the operational WSR88Ds. So, the vertical extents of inflows obtained with the operational WSR-88D can be underestimated.

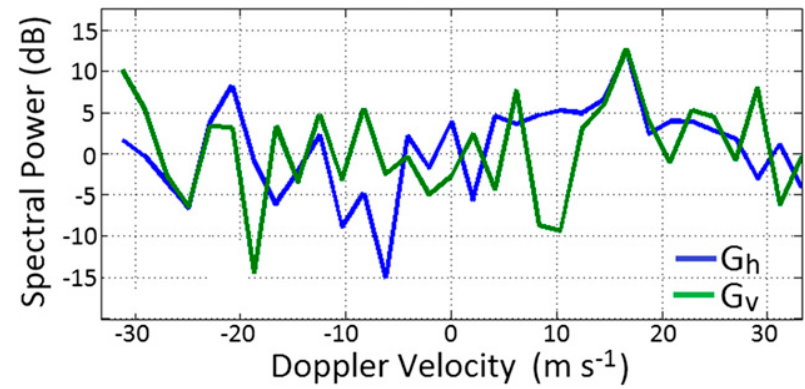

FIG. 5. Doppler spectra at horizontal $\left(G_{h}\right)$ and vertical $\left(G_{v}\right)$ polarizations in a radar volume at $41.5 \mathrm{~km}$, azimuth of $287^{\circ}$, and elevation of $4^{\circ}$. The data were collected at 2315 UTC 31 May 2013.

The spectral powers are in the internal processor units. 
Acknowledgments. We thank Dr. T. Schuur for fruitful discussions. V. M. is grateful to the members of working groups 2 and 4 of the European Network for the Radar Surveillance of Animal Movement (ENRAM) for the discussions of the findings at the meeting in July 2014. Funding was provided by the NOAA/Office of Oceanic and Atmospheric Research under NOAAUniversity of Oklahoma Cooperative Agreement NA11OAR4320072, U.S. Department of Commerce.

\section{REFERENCES}

Achtemeier, G. L., 1991: The use of insects as tracers for "clear-air" boundary-layer studies by Doppler radar. J. Atmos. Oceanic Technol., 8, 746-765, doi:10.1175/1520-0426(1991)008<0746: TUOIAT $>2.0 . \mathrm{CO} ; 2$.

Browning, K. A., 1982: General circulation of middle-latitude thunderstorms. Thunderstorm Morphology and Dynamics, E. Kessler, Ed., Vol. 2, Thunderstorms: A Social, Scientific, and Technological Documentary. U.S. Dept. of Commerce, 211-247.

_ 1983: Morphology and classification of middle-latitude thunderstorms. Thunderstorms Morphology and Dynamics, Ed. E. Kessler, Vol. 2, Thunderstorms: A Social, Scientific, and Technological Documentary. U.S. Dept. of Commerce, 133-152.

Burgess, D. W., and L. R. Lemon, 1990: Severe thunderstorm detection by radar. Radar in Meteorology, D. Atlas, Ed., Amer. Meteor. Soc., 619-647.

Drake, V. A., and D. Reynolds, 2012: Radar Entomology: $O b$ serving Insect Flight and Migration. CABI, 489 pp.

Melnikov, V., and P. T. Schlatter, 2011: Enhancing sensitivity on the polarimetric WSR-88D. 27th Conf. on Interactive Information and Processing Systems (IIPS), Seattle, WA, Amer. Meteor. Soc., 14.3. [Available online at http://ams.confex.com/ ams/91Annual/webprogram/Paper178856.html.]
— M. Leskinen, and J. Koistinen, 2014: Doppler velocities at orthogonal polarizations in radar echoes from insects and birds. IEEE Geosci. Remote Sens. Lett., 11, 592-596, doi:10.1109/ LGRS.2013.2272011.

Metcalf, J. I., 1986: Interpretation of the autocovariances and cross-covariance from a polarization diversity radar. J. Atmos. Sci., 43, 2479-2498, doi:10.1175/1520-0469(1986)043<2479: IOTAAC $>2.0 . \mathrm{CO} ; 2$.

Murphey, H. V., R. M. Wakimoto, C. Flamant, and D. E. Kingsmill, 2006: Dryline on 19 June 2002 during IHOP. Part I: Airborne Doppler and LEANDRE II analyses of the thin line structure and convection initiation. Mon. Wea. Rev., 134, 406430, doi:10.1175/MWR3063.1.

Schiesser, H. H., and A. Waldvogel, 1999: Hailstorms. Storms, R. Pielke Jr. and R. Pielke Sr., Eds., Vol. 2, Routledge, 133-145.

Snyder, J. C., and H. B. Bluestein, 2014: Some considerations for the use of high-resolution mobile radar data in tornado intensity determination. Wea. Forecasting, 29, 799-827, doi:10.1175/ WAF-D-14-00026.1.

Wakimoto, R. M., H. V. Murphey, R. G. Fovell, and W.-C. Lee, 2004: Mantle echoes associated with deep convection: Observations and numerical simulations. Mon. Wea. Rev., 132, 1701-1720, doi:10.1175/1520-0493(2004)132<1701: MEAWDC $>2.0 . \mathrm{CO} ; 2$.

Wilson, D. R., A. J. Illingworth, and T. M. Blackman, 1997: Differential Doppler velocity: A radar parameter for characterizing hydrometeor size distributions. J. Appl. Meteor., 36, 649-663, doi:10.1175/1520-0450-36.6.649.

Wilson, J. W., T. M. Weckwerth, J. Vivekanandan, R. M. Wakimoto, and R. W. Russell, 1994: Boundary layer clear-air radar echoes: Origin of echoes and accuracy of deriving winds. J. Atmos. Oceanic Technol., 11, 1184-1206, doi:10.1175/1520-0426(1994)011<1184: BLCARE $>2.0 . \mathrm{CO} ; 2$.

Zrnić, D. S., and A. V. Ryzhkov, 1999: Polarimetry for weather surveillance radars. Bull. Amer. Meteor. Soc., 80, 389-406, doi:10.1175/1520-0477(1999)080<0389:PFWSR >2.0.CO;2. 